\title{
Cenários prospectivos: o caso do rompimento da barragem em Mariana (MG)
}

Michele Gomes Lopes ${ }^{1}$ José Eduardo Zdanowicz ${ }^{2}$

\section{Resumo}

O presente artigo objetiva analisar e avaliar a relevância de serem elaborados cenários prospectivos, para evitar consequências como as do rompimento da barragem em Mariana, Minas Gerais, Brasil. A pesquisa caracteriza-se por ser um estudo de caso exploratório e bibliográfico, utilizando o método qualitativo. Os dados foram coletados em relatórios disponíveis, e os resultados descrevem as consequências do desastre, as quais estão sendo minimizadas por meio das ações corretivas da Samarco S. A. em conjunto com o governo. Essas ações têm como base a segurança e a responsabilidade socioambiental. A principal conclusão foi a de que, mesmo com os esforços da mineradora, os danos não foram sanados, e a recuperação da região será uma recuperação lenta, a longo prazo. Esse foi considerado o maior desastre ambiental do mundo, portanto, é fundamental a colaboração governamental para mitigar os impactos, bem como evitar eventos semelhantes.

Palavras-chaves: Cenários prospectivos. Responsabilidade socioambiental. Rompimento de barragem.

\begin{abstract}
This article aims to analyze and evaluate the relevance of preparing future scenarios to avoid the consequences as the dam break in Mariana, Minas Gerais, Brazil. The research is characterized by being a study of exploratory and bibliographical case, using the qualitative method. Data were collected from available reports. The results describe that the disaster consequences are minimized through the corrective actions of Samarco S.A. and the Government. These actions are based on safety and environmental responsibility. The main conclusion was that, even with the efforts of the mining company, it is believed that the damage can not be corrected and it will have a long-term slow recovery. This was considered the biggest environmental disaster in the world. So, government cooperation is essential to mitigate the impacts and to prevent similar events.
\end{abstract}

Keywoards: Prospective scenarios. Environmental responsibility. Dam Breaking.

\footnotetext{
${ }^{1}$ Acadêmica do Curso de Administração das Faculdades Integradas de Taquara (Faccat/RS), michelegomes.lopes@hotmail.com

2 Doutor em Administração e Gestão de Empresas pela Universidade de León, Espanha. Professor na Faculdades Integradas de Taquara (Faccat/RS) e Universidade Fededral do Rio Grande do Sul (UFRGS). profeduardoz@hotmail.com
} 


\section{Introdução}

A sociedade está em constante evolução, pois o uso de tecnologias cresce cada vez mais, impulsionando, assim, transformações sociais, culturais, políticas, científicas e, consequentemente, ambientais. Em um cenário cada vez mais complexo, é preciso preparar-se para as mudanças que podem ocorrer, por isso é importante se antecipar a imprevistos e eventos turbulentos para minimizar os danos que eles podem causar à sociedade.

O presente artigo evidencia a importância da utilização de cenários prospectivos como ferramenta para mitigar os riscos e as perdas que eventos inesperados possam ocasionar. Os cenários visam estudar alternativas para o futuro, elaborando estratégias para cada situação. Assim, quando as situações projetadas ocorrerem, o analista de cenários prospectivos terá algumas soluções para atuar sobre elas.

O estudo aborda, especificamente, o caso do rompimento da barragem em Bento Rodrigues, no município de Mariana (MG), em 5 de novembro de 2015, quando uma onda gigante de lama se formou e devastou as cidades próximas à barragem, causando grandes danos ao meio ambiente local, perdas humanas e destruição de infraestruturas, gerando imensos prejuízos econômicos. A problematização deste estudo de caso é analisar quais cenários prospectivos deverão ser elaborados para sanar os impactos causados pelo rompimento da barragem em Mariana (MG).

A questão justifica-se pela comoção, pela sensibilização que o desastre provocou, pois, atualmente, as pessoas atingidas passam por muitas dificuldades, entre as quais a falta de moradia e a insegurança, além dos prejuízos econômicos e danos psicológicos. Outro interesse no desenvolvimento deste estudo é avaliar as medidas e ações corretivas que a Mineradora Samarco S. A. está implantando para a recuperação do meio ambiente e no atendimento aos atingidos.

O objetivo geral desta pesquisa é, através da visão prospectiva, elaborar cenários para a erradicação das consequências do referido desastre no horizonte 2017-2021. Portanto, é de suma importância para a compreensão deste caso estudar as causas do rompimento, para mapear suas consequências, identificando os fatores críticos atuais para analisar as ações corretivas que a Mineradora está implantando ou irá implantar.

Quanto ao procedimento de pesquisa, foram utilizados os métodos monográfico, bibliográfico e exploratório. Para elaboração de cenários, utilizou-se o método Godet, por ser o mais adequado à pesquisa exploratória. Da mesma forma, caracteriza-se como um estudo de caso, tendo a pesquisa uma abordagem dedutiva e a forma de análise qualitativa, com dados secundários.

O estudo auxilia a compreensão do conceito de cenários prospectivos, sua importância e tipologia, contribuindo, mesmo que minimamente, para o conhecimento e desenvolvimento de acadêmicos, sendo exemplo e referência para as gerações futuras, sensibilizando o leitor acerca das dificuldades que as vítimas enfrentaram. 


\section{Caracterização do caso}

O rompimento de barragens é um risco constante para o setor de extração mineral. Mesmo com esses riscos, normalmente, há pouca atenção a esses eventos aqui no Brasil, pois pouco estudo se possui sobre o assunto. Entretanto, um relatório publicado em dezembro de 2015 por Milanez et al. (2015) foi utilizado como base na presente pesquisa e apresentação do caso. No dia 5 de novembro de 2015, no subdistrito Bento Rodrigues, localizado no município de Mariana, em Minas Gerais, Brasil, rompeu-se a Barragem de Fundão. A responsável pela barragem é a Samarco S. A., empresa brasileira de mineração, de capital fechado, e controlada por dois acionistas em partes iguais: BHP Billiton Brasil Ltda. e Vale S. A.

A Mineradora possui sede em Belo Horizonte (MG), e se dedica às atividades de pelotização, sinterização e outros beneficiamentos de minério de ferro; exporta para dezenove países das Américas, Oriente Médio, Ásia e Europa. Foi fundada em 1977, e, desde a década de 1990, passou por contínuas etapas de expansão. Além da barragem rompida, a Mineradora é responsável pelas barragens do Germano e de Santarém, também localizadas em Mariana. Quando o rompimento de Fundão ocorreu, provocou um "tsunami" de lama que devastou Bento Rodrigues e outros distritos da região de Minas Gerais, além de poluir o Rio Doce até a foz, no Estado do Espírito Santo.

A destruição foi de tal tamanho que devastou um número imenso de casas e deixou centenas de famílias desabrigadas, além de fazer vítimas mortais. Nem todos os danos são passíveis de mensurar, mas, sem dúvidas, causou impactos violentos não previstos e irreparáveis, pelo menos em curto prazo. É importante lembrar que os casos de rompimentos de barragens, em Minas Gerais, vêm acontecendo nos últimos 15 anos, como pode ser visto no Quadro 1.

\section{Quadro 1 - Acidentes recentes de barragens em Minas Gerais}

\begin{tabular}{|l|l|l|l|}
\hline Ano & Empresa Responsável & Cidade & Consequencias \\
\hline 2001 & Mineração Rio Verde & Nova Lima/MG & $\begin{array}{l}\text { Cinco mortes, danos à fauna, flora e } \\
\text { unidade de conservação, danos a } \\
\text { adutoras de abastecimento de água, } \\
\text { assoreamento de rios. }\end{array}$ \\
\hline 2002 & Indústria Cataguases de Papel & Cataguases/MG & $\begin{array}{l}\text { Contaminação do Rio Pomba e } \\
\text { Interrupção no fornecimento de água. }\end{array}$ \\
\hline 2006 & Rio Pomba Mineração Cataguases & Miraí/MG & $\begin{array}{l}\text { Danos ambientais, prejuízos materiais, } \\
\text { suspensãodo abastecimentode águaem } \\
\text { cidades de MG e RJ. }\end{array}$ \\
\hline 2007 & Rio Pomba Mineração Cataguases & Miraí/MG & $\begin{array}{l}\text { Danos ambientais, prejuízos materiais, } \\
\text { suspenção do abastecimento de água, } \\
\text { mais de 500 pessoas desalojadas. }\end{array}$ \\
\hline 2015 & Samarco & Itabitiro/MG & $\begin{array}{l}\text { Três trabalhadores mortos e danos } \\
\text { ambientais. }\end{array}$ \\
\hline
\end{tabular}

Fonte: Comissão Extraordinária de Barragens (2015-2016). 
Assim, mesmo possuindo esse histórico de acidentes com barragens, o Estado não parece estar aprendendo com as consequências, já que não existem equipes profissionalizadas e legitimadas pelo poder público, para trabalhar na reparação dos impactos causados e produzir conhecimento a ser utilizado na prevenção de acidentes futuros, visto que os erros cometidos são semelhantes, ou seja, são negligenciados os mesmos itens da legislação, juntamente com a baixa presença dos órgãos públicos fiscalizadores de atividades de minério.

\section{Fundamentação teórica}

A humanidade é vulnerável aos acontecimentos, os quais podem ocorrer devido à imprevisibilidade do futuro. Em razão disso, é importante planejar estrategicamente as ações que devem ser tomadas quando ocorrerem mudanças inesperadas. Esse planejamento pode ocorrer por meio de ferramentas que contribuam para seu desenvolvimento. Assim, busca-se entender o conceito de cenários como uma ferramenta que, segundo Schwartz (2003), é um auxílio para estender a visão ao futuro, em um mundo cheio de incertezas. De acordo com o autor, a elaboração de cenários aconteceu após a Segunda Guerra Mundial, em 1945, como um método de planejamento militar. Schwartz explica que, nos anos 70, o tema foi levado a uma nova dimensão através do trabalho de Pierre Wack $^{3}$, que, com outros planejadores, criou cenários para as alterações possíveis no preço do petróleo. Em seguida, no ano de 1973, houve uma alta no preço, e a crise de energia se arrastou pelo mundo, mas, dentre as maiores companhias de petróleo, uma estava emocionalmente preparada para tal acontecimento: a Royal Dutch/Schell (SCHWARTZ, 2003).

Para Bethlem (2004), o conceito de cenários consiste na elaboração de sequências hipotéticas de situações complexas, por meio de textos escritos, a fim de concentrar a atenção em processos causais e pontos de decisão, facilitando, assim, a decisão perante as incertezas e a falta de conhecimento. E explica que a construção de cenários se tornou cada vez mais utilizada, porque as projeções são baseadas em combinações de variáveis de diversas naturezas e origens, tais como econômicas, sociais, políticas, tecnológicas, etc. Todavia, devido à grande quantidade de variáveis existentes para a construção de cenários, é difícil sua compreensão e elaboração, pois o número de combinações ratificáveis de cada uma das variáveis pode se tornar impossível de manejar.

Com base nas incertezas, Heijden (2004) explica que, para uma decisão ser tomada, a incerteza deve ser avaliada. Acredita que a elaboração de cenários prospectivos auxilia o acompanhamento do que pode ocorrer, bem como as consequentes mudanças do ambiente. Assim, os analistas de cenários podem prever se uma incerteza é plausível ou não.

Contudo, ao se tratar de incertezas, não se deve deixar de levar em consideração a famosa Lei de Murphy, que diz que "[...] se alguma coisa puder dar

\footnotetext{
${ }_{3}^{3}$ Planejador estratégico da Royal Dutch/Schell na década de 70.
} 
errado, dará", ou seja, tudo que tiver que acontecer, independente do que se faça para evitar, acontecerá. Essa lei teve origem há mais de dois séculos, mas só ganhou reconhecimento nos anos 40, ao ser citada por Edward A. Murphy Jr, engenheiro do desenvolvimento na aeronáutica dos Estados Unidos da América na época (REVISTA GALILEU, 2003).

No Brasil, a construção de cenários surgiu nos anos 80 , mas foi na década de 90 que o seu uso se expandiu, passando a ser utilizada pelas organizações. Assim, emergiram as consultorias voltadas à elaboração de cenários, bem como existem entidades de ensino, empresas estatais e órgãos do governo que possuem centros dedicados ao estudo e à elaboração de cenários (BETHLEM, 2004).

Sobre o horizonte de tempo de um cenário, Marcial e Grumbach (2008) explicam que pode variar em função do sistema estudado. Normalmente, deve ser de 10 anos. E, por sua vez, recomenda a elaboração de cenários em um horizonte de tempo menor que 5 anos, mas isso depende do objetivo do estudo. Para fim explicativo, o horizonte de tempo nada mais é do que o período que o estudo irá cobrir.

Planejar cenários prospectivos é uma tentativa de analisar e prospectar o futuro. Para isso, busca-se elaborar estratégias a fim de se lidar com as incertezas e os eventos imprevisíveis. Para a construção dos cenários, deve-se conhecer o método mais adequado para o tipo de cenário que se deseja elaborar. Assim, serão apresentados a seguir, de forma breve, alguns dos principais métodos e suas respectivas etapas, elucidados por Marcial e Grumbach (2008):

- Método de Godet (1993): é um método exploratório de elaboração de cenários onde, inicialmente, delimita-se um sistema. É delimitado pelo objeto de estudo, pelo horizonte temporal e pela área geográfica. Junto à delimitação do sistema, ocorre a do ambiente, que é um contexto mais amplo, onde ambos se influenciam mutuamente.

Elabora-se uma lista das variáveis relevantes do sistema e seus atores, para dar início à fase de análise estrutural, bem como de uma análise retrospectiva do sistema e da situação atual. Através dessas análises, obtêm-se as condicionantes do futuro, onde são listadas as tendências de peso, os fatos portadores do futuro, os fatores predeterminados e as invariantes e uniões entre os atores. No passo seguinte, são elaborados os cenários, baseados nas condicionantes do futuro, ou seja, descreve-se o encaminhamento da situação atual e o horizonte escolhido.

Em seguida, são feitos testes de consistência, etapa na qual são realizados os ajustes necessários para manter a coerência da história escrita. Já na última etapa desse método, os cenários devem ser analisados, para a identificação dos pontos fortes e fracos, bem como as oportunidades e ameaças apresentadas para a organização. Isso facilita a tomada de decisões e a definição de estratégias.

- Método de Schrwartz (1995): é conhecido como o método da Global Business Network, uma empresa norte-americana, fundada por Peter Schwartz, nos anos 80. Schwartz é um ex-funcionário da Royal Dutch Shell. É um método ba- 
seado em oito etapas, sendo a primeira delas a identificação da questão principal do estudo. Define-se como principal a questão que motivou a elaboração dos cenários. Na segunda etapa, identificam-se, através de uma lista, os fatores-chave, ou seja, as principais forças do ambiente, ressaltando que esses fatores incluem clientes, concorrentes, fornecedores, volatilidade e outros. Em seguida, definemse as forças menos óbvias de identificação, mas que influenciam os fatores-chave, as chamadas "forças motrizes" (MARCIAL; GRUMBACH, 2008).

Depois de identificadas as forças motrizes, separam-se os elementos predeterminados (eventos com ocorrência certa) das incertezas críticas (variáveis incertas). Nessa etapa, é preciso identificar as incertezas e atribuir um número para cada uma delas, de acordo com seu grau de incerteza, por isso o nome ranking por importância e incerteza. Já na próxima etapa, chamada de seleção das lógicas dos cenários, é feita uma análise de comportamento das incertezas críticas, as quais são posicionadas nos eixos ao longo da descrição dos cenários. Marcial e Grumbach (2008) explicam que essa é a etapa mais importante na elaboração de cenários e ressalta que se devem testar diversos eixos, para então escolher com quais eixos se quer trabalhar. Em seguida, na sexta etapa, é feita a descrição dos cenários. Para isto, utiliza-se a lista de fatores, as tendências principais, momento em que cada item dessa lista deve receber a atenção devida, e sua distribuição pelos cenários deve ocorrer de acordo com a lógica de cada um.

Os cenários devem ser apresentados de forma narrativa, detalhadamente. Logo após a elaboração dos cenários, e a partir de cada um deles, deve-se voltar à questão principal e definir estratégias e soluções. Na etapa seguinte, verificam-se as implicações e oportunidades de cada decisão, optando por estratégias melhores; essa etapa é denominada de análise das implicações e opções. Por último, a etapa de seleção de indicadores e sinalizadores principais, sendo essa a base para o elaborador de cenários saber, o mais rapidamente possível, qual dos cenários mais se aproxima da realidade; isso corre através do monitoramento das variáveis selecionadas com base na análise de cenários.

- Método Grumbach (1996): tem apoio em dois softwares, um chamado "Puma", que é um sistema de planejamento estratégico e cenário prospectivo, e o software "lince", que é um sistema de simulação e gestão de futuro. O método Grumbach é conceituado como um planejamento estratégico, com visão de futuro, que se baseia em cenários prospectivos, e em análise de parcerias estratégicas, baseada no diagnóstico de novos fatos adquiridos por inteligência competitiva. Esse método é composto por quatro fases. A primeira é a identificação do sistema, que utiliza como base os cenários prospectivos para definir o sistema objeto. Na segunda fase, a do diagnóstico estratégico, o objetivo é identificar os fatos portadores de futuro, através de uma visão detalhada das questões ligadas tanto ao sistema quanto ao ambiente no qual se encontra. Já a terceira fase, a da visão estratégica, abrange três etapas: a) a visão do presente: análise das causas e consequências dos fatos portadores de futuro; b) a visão do futuro: construção de cenários, utilizando técnicas de brainstorming, Delphi, impactos cruzados e 
simulação de Monte Carlo, bem como as simulações e a análise de parcerias estratégicas; c) avaliação de medida e gestão de resistências (MARCIAL; GRUMBA$\mathrm{CH}, 2008$ ). Na quarta e última fase, são definidos os direcionadores estratégicos, baseados na visão e na elaboração de planos. Quanto à utilização dos softwares, em todas as quatro fases, utiliza-se o "Puma", mas apenas na segunda etapa da fase visão estratégica é que é aplicado o "Lince" também, de acordo com Marcial e Grumbach (2008).

As metodologias de elaboração de cenários, mesmo seguindo uma sequência lógica parecida, possuem dois conjuntos distintos, de acordo com o tratamento analítico, os quais podem diferenciá-las, sendo eles o processo indutivo e o processo dedutivo (BUARQUE, 2003). Para o autor, o método indutivo parte do particular para o geral, ou seja, os cenários são elaborados a partir da exploração da criatividade, da combinação de hipóteses sobre os principais eventos. Já o método dedutivo parte do geral para o particular, descobrem-se estruturas de futuro, a partir de dados e informações gerados pelos eventos, e constitui-se um marco geral, gerando os cenários. É valido ressaltar que, quando se dá referência aos métodos de modo geral, pode-se notar que os passos para a construção de cenários são semelhantes em todos os métodos.

Souza (2012) destaca, em seu artigo "A visão do futuro por meio de cenários prospectivos: uma ferramenta para antecipação da inovação disruptiva", as vantagens e algumas delimitações na utilização do método de cenários prospectivos. No quadro elaborado por Souza, utilizam-se, como base, os autores Durance e Godet; Marcial e Grumbach; Mietzner e Reger; Schoemaker, Schwab, Cerutti e Von Reibnitz e, Schwartz. Sendo assim, apresentam-se, inicialmente, as vantagens. Considera nove itens como vantagens: cenários vão além de análises objetivas, incluindo interpretações subjetivas; cenários utilizam possibilidade em narrativas, facilitando sua compreensão; cenários possibilitam muito futuros desejáveis e concebíveis; cenários abrem a mente, para imaginar coisas inimagináveis, e, consequentemente, os gerentes precisam repensar suas estratégias; cenários ajudam a reconhecer sinais de fraquezas, descontinuidades tecnológicas ou eventos disruptivos, colocando-os no planejamento de longo prazo; cenários melhoram a comunicação, ao criarem uma linguagem simples para lidar com as estratégias; o compartilhamento de informações, no processo de construção de cenários, melhora o aprendizado organizacional e a tomada de decisão; cenários podem ser flexíveis e adaptáveis às situações específicas; cenários conjugam o conhecimento tácito dos cenaristas às projeções formuladas.

Já em relação às limitações, foram ressaltados seis itens, de acordo com Souza (2012): a percepção de planejadores pode afetar os cenários; pode haver negligência na pesquisa dos dados e das informações na elaboração dos cenários; não é uma tarefa fácil, portanto umaabordagem qualitativa deve garantir a adequabilidade dos peritos selecionados; o processo de elaboração consome tempo; as pessoas que elaboram os cenários podem mudar durante seu processo; há a tendência de algumas pessoas focarem em cenários mais prováveis.

Dessa forma, nota-se que o estudo de cenários prospectivos facilita o de- 
senvolvimento estratégico, bem como auxilia a compreensão e a visão global do ambiente, além de, aparentemente, facilitar as trocas de informações e desenvolver a criatividade dos envolvidos (MARCIAL; GRUMBACH, 2008). A definição de estratégias, através da elaboração de cenários prospectivos, em um ambiente incerto, é de grande importância para quem não possui instrumentos apropriados para lidar com as turbulências. A autora ressalta que "[...] quanto maior a incerteza, maior a probabilidade de as previsões não ocorrerem". E, ainda, sugere que isso cause críticas a respeito dos estudos prospectivos, mas justifica que o fato de essas falhas ocorrerem surge da necessidade do homem querer prever aquilo que não é possível ser previsto.

\section{Estudo de caso}

Quando a barragem se rompeu, em dezembro de 2015, além de causar destruição por onde passou, a lama chegou ao Rio Doce, acarretando significativa perda da biodiversidade, bem como contaminação da água. Dessa forma, pode-se notar como se está suscetível às incertezas, as quais podem ocorrer e ocasionar prejuízos incontáveis, como no caso de Mariana (MG), visto que todos esses impactos imediatos afetaram também, economicamente, o Estado de Minas Gerais, já que muitas famílias perderam seus bens materiais, principalmente as pessoas que dependiam do local para sobreviver, como pescadores, garimpeiros e agricultores.

No entanto, a Mineradora Samarco S. A., responsável pela barragem, afirma ter sido feita uma inspeção, em julho de 2015, pela Superintendência Regional de Meio Ambiente e Desenvolvimento Sustentável (SUPRAM), que demonstrava estar o local apto a operar. Em junho de 2016, a Polícia Federal concluiu o inquérito que investigava as causas para o rompimento da Barragem de Fundão, em Mariana - MG, no qual listam diversos motivos, entre eles sobrecarga de rejeitos ${ }^{4}$, falhas no monitoramento, equipamentos com defeitos, deficiência no sistema de drenagem interno e assoreamento ${ }^{5}$, além de falhas técnicas. Assim, a polícia pediu a prisão de sete pessoas, e, em outubro de 2016, o Ministério Público Federal (2016) denunciou à justiça 21 pessoas por homicídio doloso, que ocorre quando se assume o risco de cometer o crime, entre outras transgressões como inundações, lesões corporais graves e desabamentos. Entre os denunciados, estão o presidente, alguns diretores, gerentes e integrantes do Conselho de Administração da mineradora, além de cinco representantes de suas controladoras (Vale e BHP Billiton).

Para proporcionar ao leitor maior compreensão da dimensão do desastre em Minas Gerais, foram separadas algumas imagens que mostram a destruição

\footnotetext{
${ }^{4}$ Rejeitos são resíduos de mineração que resultam dos processos de beneficiamento a que se submetem os minérios.

5 Acúmulo de sedimentos, de terra, de areia, de detritos, num rio, canal, lago, etc., causado pelas águas das enchentes, geralmente resultado do uso incorreto do solo, dos desmatamentos, das monoculturas ou de ações evasivas que prejudicam o ambiente.
} 
causada pelo "tsunami" de lama. Na Figura 1, nota-se o cenário de destruição em um vilarejo de Mariana que foi arrastado pela lama. Somente os destroços sobraram no local. De acordo com o site da ONUBR (2015), mais de 62 milhões de metros cúbicos foram arrebatados sobre Mariana. Além de mortes causadas pelo desastre, houve, também, danos intermediários, como falta de água e perda de fontes de renda pela contaminação do solo e da água.

\section{Figura 1 - Cidade destruída pela lama}

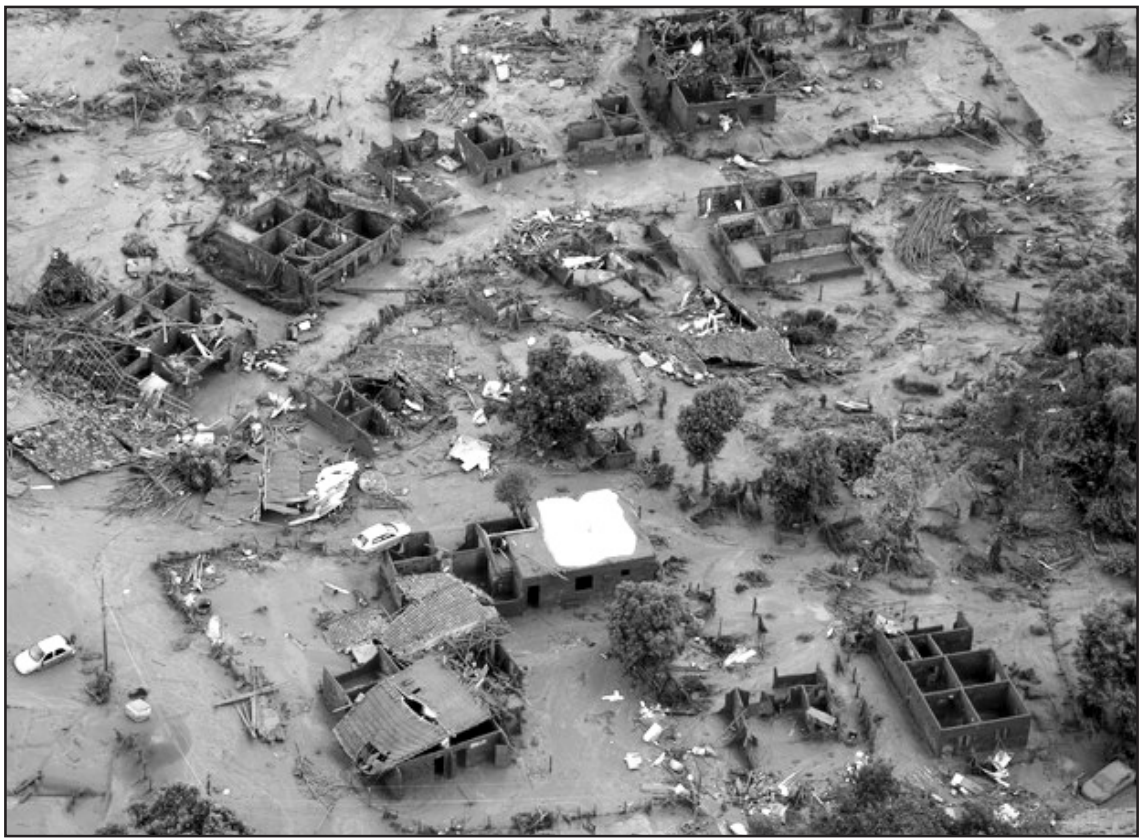

Fonte: ONUBR (2015).

A Figura 2, que mostra o antes e depois do rompimento da barragem, é uma imagem de satélite. Através dessa foto, pode-se observar a região de Bento Rodrigues em situação desastrosa, ressaltando que foi a região mais atingida pela lama.

Diante disso, foi feito um acordo entre a Samarco S. A. e suas controladoras e a Advocacia Geral da União (AGU), em novembro de 2015, para que destinassem 20 bilhões, ao longo dos próximos 10 anos, para a recuperação do Rio Doce e indenização às comunidades. No entanto, em julho de 2016 , o acordo foi suspenso pelo Superior Tribunal de Justiça. A decisão foi tomada pela ministra Diva Malerbi, afirmando que a homologação do referido acordo pela autoridade desrespeitou a decisão da Corte Superior. A Samarco S. A. divulgou, em seu site, no dia 19 de maio de 2016, um balanço com as principais ações corretivas, conforme Quadro 2. 
Figura 2 - Antes e depois do rompimento da barragem

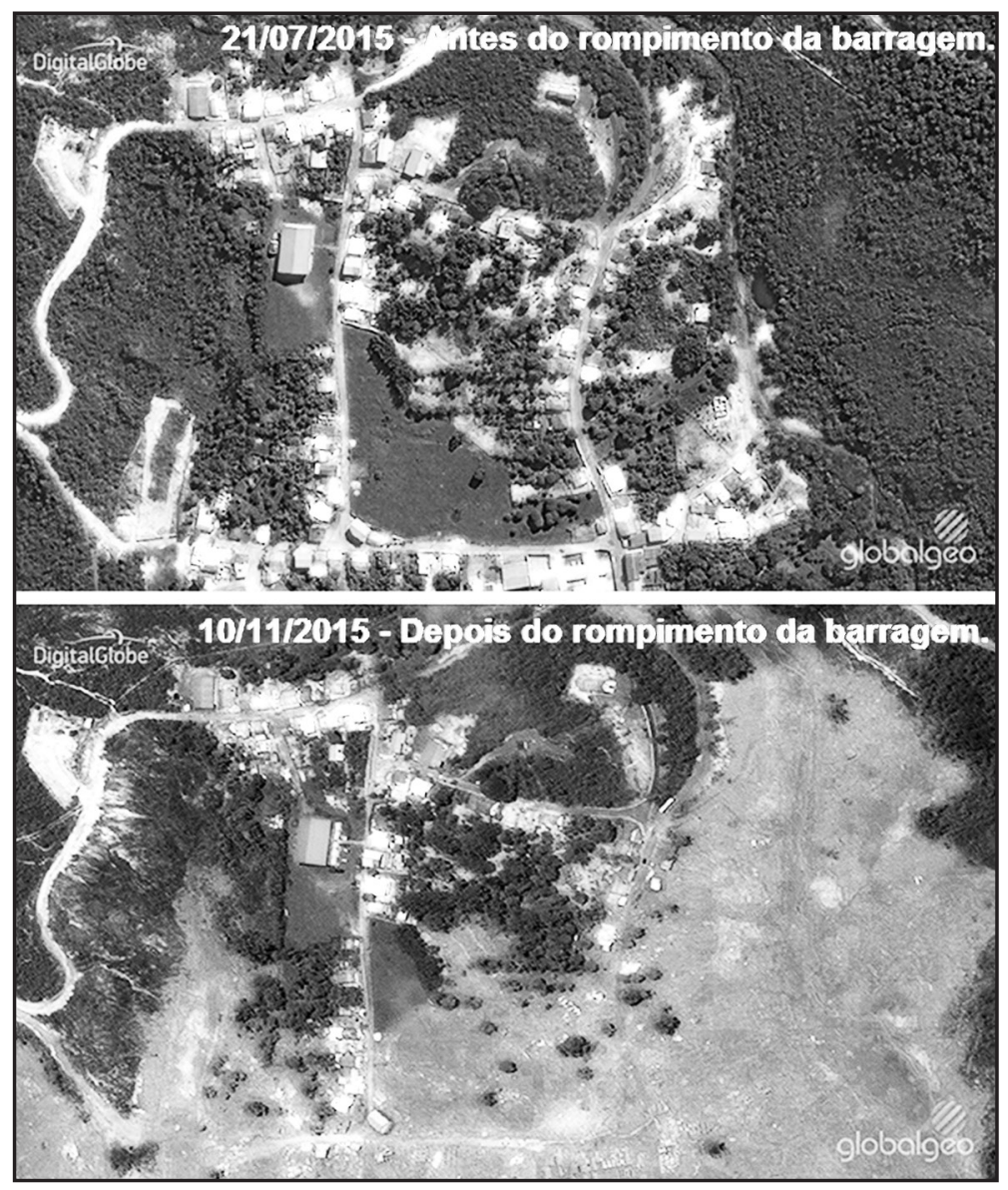

Fonte: Adaptado de O tempo (2015).

Vale ressaltar que, em agosto de 2016, o Tribunal de Justiça de Minas Gerais (2016) informou que as todas as licenças ambientais do Complexo Germano foram suspensas. O juiz responsável pela decisão reconheceu a importância do funcionamento da mineradora para a localidade, mas isso não justificava a retomada de atividades, com riscos de novas tragédias, já que ela pretendia voltar a operar com as mesmas licenças ambientais obtidas antes do rompimento, mesmo não possuindo eficácia. O IBAMA aplicou a sétima multa, no valor de 1 miIhão de reais, pois, apesar de cumprir os prazos estabelecidos, a mineradora não mostrou soluções para algumas situações, como, por exemplo, a lama, retirada em apenas $10 \%$ em um ano, ou seja, o restante continua espalhado pelas ruas e às margens dos rios. Dessa forma, a Samarco pediu novo prazo para a retirada da lama, no entanto, o pedido foi recusado. 
Quadro 2 - Balanço das principais ações corretivas

\begin{tabular}{|c|c|}
\hline Ações corretoras feitas & Ações a fazer \\
\hline $\begin{array}{l}\text { Familias realocadas em acomodações } \\
\text { temporárias; }\end{array}$ & Disponibilização de recursos para alguns municípios; \\
\hline $\begin{array}{l}\text { Escolha do local para reconstrução de } \\
\text { Bento Rodrigues; }\end{array}$ & Recuperação de 5 mil nascentes; \\
\hline $\begin{array}{l}\text { Todos os alunos concluíram o ano letivo de } \\
2015 \text { e iniciaram o ano de } 2016 ;\end{array}$ & $\begin{array}{l}\text { Recuperação de Áreas de Proteção Permanente do Rio } \\
\text { Doce; }\end{array}$ \\
\hline 800 hectares de áreas revegetadas; & $\begin{array}{l}\text { Reflorestamento de } 10 \text { mil hectares e condução de } \\
\text { regeneração natural de } 30 \text { mil hectares ao longo de } 10 \\
\text { anos; }\end{array}$ \\
\hline Monitoramento da qualidade da água; & Reconstrução das localidades impactadas; \\
\hline $\begin{array}{l}\text { Reconstrução de todas as pontes } \\
\text { danificadas; }\end{array}$ & $\begin{array}{l}\text { Execução de um programa de ressarcimento e } \\
\text { indenizações; }\end{array}$ \\
\hline $\begin{array}{l}\text { Entrega de cartões de auxilio-financeiro } \\
\text { aos impactados; }\end{array}$ & $\begin{array}{l}\text { Recuperação de bens culturais, materiais, e sua } \\
\text { preservação; }\end{array}$ \\
\hline \multirow[t]{5}{*}{$\begin{array}{l}\text { Barragem são monitoradas em tempo real } \\
\text { e estão estáveis. }\end{array}$} & $\begin{array}{l}\text { Implementação de ações auxiliando na recuperação de } \\
\text { atividades econômicas e produtivas prejudicadas; }\end{array}$ \\
\hline & $\begin{array}{l}\text { Implentação e manutenção de medidas de apoios aos } \\
\text { povos indígenas impactados; }\end{array}$ \\
\hline & $\begin{array}{l}\text { Criação de canais permanentes para facilitar o diálogo } \\
\text { com a comunidades; }\end{array}$ \\
\hline & $\begin{array}{l}\text { Divulgação do andamento e dos resultados dos } \\
\text { programas a serem implementados; }\end{array}$ \\
\hline & $\begin{array}{l}\text { Restabelecimento de serviços públicos, como programas } \\
\text { de saúde, proteção social e educação. }\end{array}$ \\
\hline
\end{tabular}

Fonte: Adaptado de Samarco S. A. (2016).

De acordo com Tarapanoff (2001), existem fatores que podem comprometer todo o sucesso de um plano, os quais devem ser considerados críticos, pois são determinantes para o melhor desempenho na implantação de um plano de ação. Ou seja, são áreas de um determinado processo que, ao alcançarem resultados satisfatórios, assegurarão um desempenho superior, não comprometendo o sucesso de um plano ou de uma estratégia.

Nesse caso, foram enunciados alguns fatores (vide Quadro 3) considerados críticos para o sucesso do plano de ações corretivas elaborado pela Samarco S. A., com base no dossiê divulgado pela mineradora, em 19 de maio de 2016, que expõe detalhadamente cada ação, auxiliando na escolha dos FCS. 
Quadro 3 - Fatores Críticos de Sucesso

\begin{tabular}{|l|l|}
\hline FATORES CRITICOS DE SUCESSO ATUAIS SOBRE AS AÇÕES CORRETIVAS IMPLEMENTADAS \\
\hline Responsabilidade ambiental & $\begin{array}{l}\text { Recuperação de áreas de proteção; recuperação e tratamento do Rio Doce; } \\
\text { reflorestamento e revegetação das áreas impactadas; }\end{array}$ \\
\hline Cumprimento de prazos & Cumprir os prazos definidos no planejamento das ações propostas \\
\hline Saúde & $\begin{array}{l}\text { Devido aos riscos de contaminação pelo derramamento da lama, é necessário } \\
\text { o acompanhamento médico das pessoas afetadas; }\end{array}$ \\
\hline Segurança & $\begin{array}{l}\text { Faz-se necessário testes no solo e na água para garantir à comunidade } \\
\text { confiança e monitoramento das barragens para o que o evento não se repita; }\end{array}$ \\
\hline Acompanhamento e controle & $\begin{array}{l}\text { Acompanhar as ações, afim de saber se realmente estão sendo feitas e } \\
\text { resolver qualquer problema que possa aparecer, bem como manter o controle } \\
\text { para que seu desempenho seja da melhor maneira; }\end{array}$ \\
\hline Comprometimento & $\begin{array}{l}\text { Manter o comprometimento da SAMARCo SA para com à comunidade, } \\
\text { através de um comportamento ético, participativo e interativo; }\end{array}$ \\
\hline Transparência & $\begin{array}{l}\text { Comunicar à comunidade, através de canais de diálogos e publicações, o } \\
\text { desenvolvimento do plano de ações corretivas. }\end{array}$ \\
\hline
\end{tabular}

Fonte: Adaptado de Samarco S. A. (2016).

Entre as ações da Samarco, destaca-se a construção de um novo dique chamado S4, em Bento Rodrigues, ou seja, uma nova barragem para evitar novos carreamentos em épocas de chuvas como prevenção de riscos, e as obras já foram autorizadas pelo governo de Minas Gerais, mesmo com o IBAMA afirmando num laudo que a construção do S4 não será suficiente para conter a lama. O S4 gerou inúmeros protestos dos moradores que foram atingidos pelo desastre em 2015, pois, para a sua construção, será alagado um terço de Bento Rodrigues. Assim, ainda há muito a fazer, pois nem todas as ações são passíveis de serem feitas em período curto, mesmo a mineradora fazendo o possível para reduzir os prejuízos causados pelo rompimento.

\section{Resultados}

Para a elaboração dos cenários, foi utilizado o método exploratório descrito por Godet (1993), por ser o mais adequado para um estudo exploratório. Esse método está dividido em seis etapas:

\section{1ㅁ Etapa - Delimitação do sistema e do ambiente}

Com o rompimento da Barragem de Fundão, foram afetados 35 municípios no estado de Minas Gerais, e quatro no Espírito Santo, havendo danos econômicos, privados e públicos, perdas humanas e ambientais, além de danos sociais. A lama deixou muitas pessoas desabrigadas, tornou a água do Rio Doce imprópria para consumo e, ao ter contato com o solo, também o deixou infértil, além de outros danos que serão vistos no decorrer do artigo. Os cenários elaborados compreenderão o horizonte de 2017 - 2021, já que um prazo médio de tempo é o mais apropriado para este estudo. 


\section{2ํㅡㄹapa - Análise retrospectiva da situação atual}

Com finalidade de identificar os danos à infraestrutura, no Quadro 4, observam-se os prejuízos em números, com base nos municípios de Mariana, Barra Longa, Rio Doce e Santa Cruz do Escalvado, os municípios afetados diretamente.

Quadro 4 - Prejuízos à infraestrutura

\begin{tabular}{|c|c|c|c|}
\hline INSTALAÇÕES & Destruidas & Danificadas & Perdas estimadas \\
\hline Unidades Habitacionais & 389 & 94 & $\mathrm{R} \$ \quad 54.474 .300,00$ \\
\hline Instalações públicas de saúde & 2 & 0 & $380.715,00$ \\
\hline Instalações públicas de ensino & 6 & 1 & $\mathrm{R} \$ \quad 5.083 .625,00$ \\
\hline $\begin{array}{l}\text { Instalações públicas de uso } \\
\text { comunitário }\end{array}$ & 13 & 1 & $\mathrm{R} \$ \quad 7.393 .741,00$ \\
\hline Instalações públicas de obras & 32 & 2 & $\mathrm{R} \$ \quad 40.229 .850,00$ \\
\hline Totais & 442 & 98 & R\$ $107.562 .231,00$ \\
\hline
\end{tabular}

Fonte: Adaptado de Agência Minas (2016).

Entre as 389 unidades habitacionais destruídas, 90\% foram no município de Mariana, ressaltando que a barragem se localizava em Bento Rodrigues, subdistrito de Mariana. Já a maioria das casas danificadas ficava em Barra Longa, que compõe $98 \%$ das perdas estimadas. Em relação aos danos humano-sociais, Mariana destaca-se como o único município em que houve mortes, totalizando dezessete pessoas, entre moradores e trabalhadores das barragens. No Quadro 5, estão especificados os tipos e quantidades de danos humanos que ocorreram. É importante levar em consideração que os enfermos e feridos tiveram como causa, em sua grande maioria, a intoxicação por agente químico e o soterramento ou desabamento.

Em torno de 300.000 pessoas foram afetadas. O item "outros afetados" está relacionado aos que sofreram consequências indiretamente, devido à privação de água e de um meio ambiente equilibrado; alguns municípios tiveram também interrupção nos serviços de ensino, o que comprova que os serviços públicos também foram afetados.. O município com maior número de afetados indiretamente foi Governador Valadares, que obteve um total de 275.000 pessoas prejudicadas devido à falta de água.

Quadro 5 - Danos humanos diretos e indiretos

\begin{tabular}{|l|c|c|c|}
\hline DANOS & $\begin{array}{c}\text { Municípios mais } \\
\text { afetados }\end{array}$ & $\begin{array}{c}\text { Municípios Costeados } \\
\text { ao Rio Doce }\end{array}$ & Total \\
\hline Mortos & 17 & 0 & 17 \\
\hline Feridos & 256 & 0 & 256 \\
\hline Enfermos & 280 & 100 & 380 \\
\hline Desabrigados & 644 & 0 & 644 \\
\hline Desalojados & 716 & 0 & 716 \\
\hline Desaparecidos & 2 & 0 & 2 \\
\hline Outros Afetados & 8567 & 311044 & 319611 \\
\hline Total & $\mathbf{1 0 4 8 2}$ & $\mathbf{3 1 1 1 4 4}$ & $\mathbf{3 2 1 6 2 6}$ \\
\hline
\end{tabular}

Fonte: Adaptado de Agência Minas (2016). 
Muitas famílias que tinham seu sustento na agropecuária enfrentam dificuldades, pois, com a realocação dos animais atingidos que sobreviveram, diminuiu a produção de leite e carne, e os locais onde esses animais bebiam água foram comprometidos. Tornou-se impossível o uso da água dos rios, para irrigação de lavouras em propriedades rurais, prejudicando o plantio e o sustento de famílias que dependiam da agricultura, ressaltando que muitos perderam toda sua produção. $O$ desastre também causou problemas na atividade areeira, além de perdas nos areais do Rio Doce; alguns empresários tiveram, inclusive, que demitir funcionários. Já em relação à pesca, estima-se que mais de 1.500 pescadores foram atingidos.

O maior prejuízo deu-se no ramo industrial, conforme o Gráfico 1, pois contratos com empresas que fabricam peças para a mineração foram cancelados, gerando desemprego, atingindo diretamente as atividades do comércio, por causa da diminuição da renda na economia. É importante ressaltar que a paralização da Mineradora Samarco S. A. e outras também justifica esse prejuízo econômico no setor industrial.

\section{Gráfico 1 - Prejuízos econômicos privados}

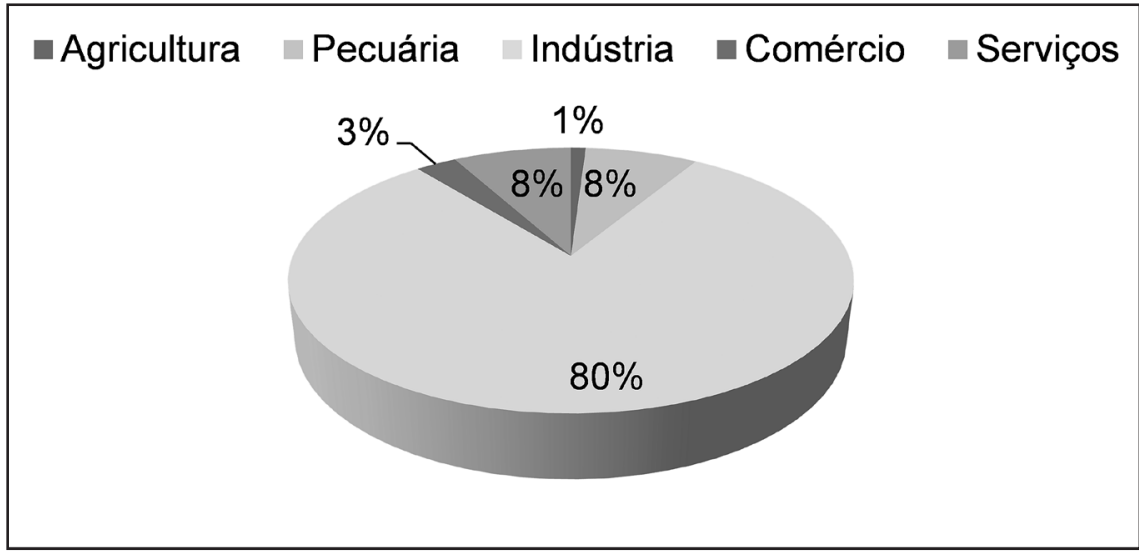

Fonte: Adaptado de Agência Minas (2016).

Quando se trata das perdas públicas, a falta de água potável foi o maior problema. De acordo com o Gráfico 2, pode-se notar que 58\% dos prejuízos foram ocasionados pelo desabastecimento de água para consumo, humano e animal, pois os locais de acesso estavam interrompidos para passagem. Dentre os municípios, Governador Valadares sofreu maior prejuízo, justamente pelo desabastecimento de água, visto ser uma das cidades atingidas com maior número de habitantes. Já a cidade de Mariana, que foi uma das mais afetadas em termos de destruição, teve seu maior prejuízo com a falta de assistência médica, saúde pública e atendimentos de emergências. 


\section{Gráfico 2 - Prejuízos econômicos públicos}

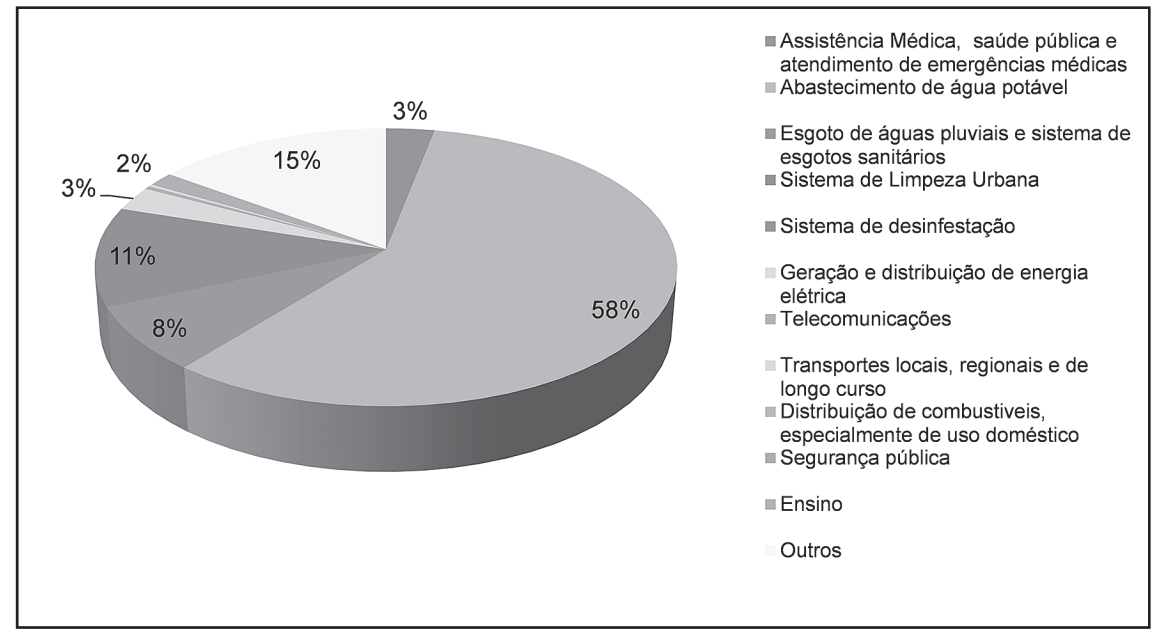

Fonte: Adaptado de Agência Minas (2016).

Já os danos ambientais ainda não foram mensurados, visto que as condições do Rio Doce podem sofrer mudanças no decorrer do tempo. Por isso, as perdas ambientais estão em fase de análise. Assim, através do relatório elaborado pela força-tarefa, em Minas Gerais (AGÊNCIA MINAS, 2016), juntamente com o laudo preliminar publicado pelo IBAMA (2016) e o relatório final, elaborado pela Comissão Extraordinária de Barragens (2015-2016), pode-se chegar aos dados conforme o Quadro 6.

\section{Quadro 6 - Danos ambientais}

\begin{tabular}{|c|c|c|}
\hline $\begin{array}{l}\text { Qualidade e disponibilidade da } \\
\text { água }\end{array}$ & $\begin{array}{c}\begin{array}{c}\text { Qualidade e disponibilidade } \\
\text { do solo }\end{array} \\
\end{array}$ & Danos sobre a biodiversidade \\
\hline - Água apresenta turbidez; & - Remodelamento do relevo; & $\begin{array}{l}\text { - Destruição de } 1.469 \text { hectares ao longo } \\
\text { de } 77 \mathrm{~km} \text { de cursos d'água, incluindo } \\
\text { áreas de preservação permanente; }\end{array}$ \\
\hline $\begin{array}{l}\text { - Características físico-química } \\
\text { discrepantes; }\end{array}$ & $\begin{array}{l}\text { - Ravinamento do solo (com } \\
\text { tendência a aumentar em } \\
\text { tempos de chuvas); }\end{array}$ & - Paisagem drasticamente modificada; \\
\hline - Assoreamento drástico dos rios; & $\begin{array}{l}\text { - Presença de metais e } \\
\text { minerais discrepantes da } \\
\text { qualidade física; }\end{array}$ & $\begin{array}{l}\text { - Perdas de espécies, piorando a } \\
\text { conservação de algumas que já estavam } \\
\text { ameaçadas; }\end{array}$ \\
\hline $\begin{array}{l}\text { - Carreamento e deposição de } \\
\text { sedimentos pela água; }\end{array}$ & - Solo infértil. & $\begin{array}{l}\text { - Comprometimento do estoque } \\
\text { pesqueiro e da estrutura e função dos } \\
\text { ecossistemas; }\end{array}$ \\
\hline \multirow[t]{3}{*}{$\begin{array}{l}\text { - Problemas de abastecimento de } \\
\text { água para fins de produção e }\end{array}$} & & - Soterramento de lagoas e nascentes; \\
\hline & & $\begin{array}{l}\text { - Destruição de vegetação ripária e } \\
\text { aquática; }\end{array}$ \\
\hline & & - Destruição de habitats. \\
\hline
\end{tabular}

Fonte: Adaptado de Agência Minas (2016). 
Quando a água apresenta turbidez, significa a redução de sua transparência, já em relação às características físico-químicas discrepantes, elas se referem aos componentes que não estão de acordo com os parâmetros estabelecidos para consumo. Quanto aos problemas de abastecimento de água, estes ocorreram devido à quantidade de materiais sedimentados nas beiras dos rios e à destruição de pontes que levavam água aos locais.

Em relação à qualidade e disponibilidade do solo, houve uma mudança no relevo, deixando-o poroso, bem como a geração de rachaduras (ravinamento) que, em épocas de chuvas, podem ocasionar erosão do solo. A presença de alguns metais pesados (alumínio, ferro, arsênio...) prejudica a condição do solo, o que torna necessário medidas de melhorias para torná-lo adequado ao uso. De acordo com o laudo preliminar do IBAMA, foram destruídos 1.469 hectares de mata florestal, entre as quais estão áreas de preservação, mata atlântica e matas ciliares, que ficam em torno dos rios, em forma de proteção. A biodiversidade também teve sua paisagem bastante modificada. O impacto da lama na extensão dos rios causou a morte de muitos peixes e, de acordo com o laudo do IBAMA, muitos deles pereceram por asfixia, devido à turbidez da água.

\section{3ㅁ Etapa-Condicionantes do futuro}

- Investimentos públicos, privados e de ensino: incentivos governamentais para as cidades atingidas. Em 3 de dezembro de 2015, foi repassado o valor de $\mathrm{R} \$$ 4,400 milhões pelo Estado, e, em 5 de maio de 2016, mais de R\$2,025 milhões. Já a Mineradora Samarco S. A. publicou, em seu dossiê, um investimento de $R \$$ 4,4 bilhões nos três primeiros anos, além de previsões de $R \$ 800$ milhões e $R \$ 1,6$ bilhão entre os anos de 2019 e 2021. Para o saneamento básico dos municípios afetados, prevê R\$ 500 milhões até 2018. Em relação ao incentivo ao ensino, é de suma importância a participação de universidades nas ações que visam a melhorias e recuperação dos danos causados, trazendo, por meio dos alunos e professores, ideias inovadoras, com tecnologias avançadas e de baixo custo, em benefício do futuro da sociedade, colocando em prática os conhecimentos adquiridos e a solidariedade.

- Monitoramento: foram montados 118 postos de monitoramento da água na bacia do Rio Doce e no oceano, e a mineradora formou uma equipe de 332 empregados para atuar frente a este controle.

- Responsabilidade socioambiental: a Samarco S. A., juntamente com a prefeitura de Mariana, conseguiu casas para aluguel, realocando as famílias atingidas. Foram distribuídas pela mineradora cestas básicas, mobília e auxílio financeiro, além de se responsabilizar pela limpeza e recuperação de alguns imóveis danificados. O IBAMA determinou à empresa que retirasse a lama em determinadas áreas, implantasse um plano de prevenção e recuperasse os danos à flora e à fauna, assim como visasse a sua proteção.

- Saúde: atendimento psicológico e assistência médica, devido às intoxicações ou ferimentos provocados pelo desastre. A Samarco S. A. contratou médicos 
para atuarem em plantões de 24 horas, e disponibilizou uma ambulância para o transporte de pacientes no município, bem como duas psicólogas e uma psiquiatra.

- Segurança: após o desastre, a Samarco S. A. alertou que havia riscos de outros duas barragens se romperem, Santarém e Germano. O site G1 divulgou imagens de rachaduras nessas barragens, e, em seguida, a mineradora iniciou as obras de emergência para evitar eventos semelhantes ao de Fundão.

\section{4ํ Etapa - Elaboração de cenários}

O objetivo dessa etapa é a elaboração dos cenários prospectivos para as consequências do desastre de Mariana, em Minas Gerais, para os anos de 2017 a 2021. Foram definidos três cenários: Cenário $A$, otimista; Cenário $B$, tendências de progressos proporcionais, o mais provável deles; Cenário $C$, contempla imprevistos e hipóteses pessimistas.

\section{Quadro 7 - Cenários prospectivos}

\begin{tabular}{|c|c|c|c|}
\hline Condicionantes & $\begin{array}{l}\text { Cenário A } \\
\text { (Otimista) }\end{array}$ & $\begin{array}{l}\text { Cenário B } \\
\text { (Realista) }\end{array}$ & $\begin{array}{c}\text { Cenário C } \\
\text { (Pessimista) }\end{array}$ \\
\hline $\begin{array}{l}\text { Investimentos públicos, } \\
\text { privados e de ensino. }\end{array}$ & $\begin{array}{l}\text { - Governo repassa } 2 \text { milhões as } \\
\text { cidades atingidas a cada } 6 \text { meses; } \\
\text { - Samarco S. A. investe acima do } \\
\text { previsto para recuperação do meio } \\
\text { ambiente e de infraestruturas. } \\
\text { - Acadêmicos de tecnologia e } \\
\text { gestão ambiental, de diversos } \\
\text { lugares do país, elaboram planos de } \\
\text { melhorias e recuperação do meio } \\
\text { ambiente voluntariamente. }\end{array}$ & 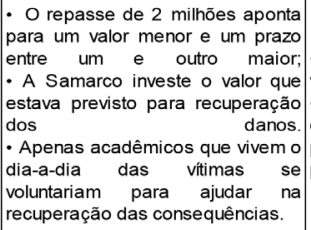 & $\begin{array}{l}\text { - O Governo para de repassar } \\
\text { valores às cidades afetadas; } \\
\text { - Crise no ramo de mineração, } \\
\text { ocasionando um valor inferior ao } \\
\text { previsto pela Samarco S. A. } \\
\text { para investimento. }\end{array}$ \\
\hline Monitoramento & $\begin{array}{l}\text { - Samarco S. A. monta mais postos } \\
\text { de monitoramento e a água se } \\
\text { apresenta apta para uso. } \\
\text { - A Mineradora publica um seu } \\
\text { plano de controle eficiente para } \\
\text { monitorar as barragens; }\end{array}$ & $\begin{array}{l}\text { - O monitoramento da água } \\
\text { continua, e a água lentamente } \\
\text { apresenta melhoria. }\end{array}$ & $\begin{array}{l}\text { - A Mineradora diminui os } \\
\text { postos de monitoramento, } \\
\text { deixando de dar assistência } \\
\text { para melhoria da água, que } \\
\text { continua imprópria para uso. }\end{array}$ \\
\hline $\begin{array}{l}\text { Responsabilidade } \\
\text { Socioambiental }\end{array}$ & $\begin{array}{l}\text { - A Mineradora aumenta o valor do } \\
\text { auxilio para as familias; } \\
\text { - Retirada de toda a lama que } \\
\text { vazou; } \\
\text { - Revegetação de toda areá } \\
\text { devastada e recuperação do Rio } \\
\text { Doce. }\end{array}$ & $\begin{array}{l}\text { - O auxilio financeiro para as } \\
\text { familias continua } \\
\text { funcionamento; } \\
\text { - Aos poucos a Samarco S. A. } \\
\text { retira a lama das estruturas que } \\
\text { sobraram inteiras; } \\
\text { - Os planos de revegetação e } \\
\text { recuperação dos danos se } \\
\text { mostram em andamento, mas os } \\
\text { resultados são estáveis. }\end{array}$ & $\begin{array}{l}\text { - Mineradora diminui o valor do } \\
\text { auxilio financeiro; } \\
\text { - Periodo intenso de chuva } \\
\text { impossibilita a retirada de lama } \\
\text { por tempo indeterminado; } \\
\text { - A recuperação Rio doce e } \\
\text { revegetação do meio ambiente } \\
\text { ocorre lenta, com apenas } 10 \% \\
\text { de sucesso. }\end{array}$ \\
\hline Saúde & $\begin{array}{l}\text { - Os plantões de atendimento } \\
\text { continuam funcionando diariamente; } \\
\text { - Atendimento psicológico e } \\
\text { psiquiatrico continua, e as vítimas } \\
\text { apresentam melhoras. }\end{array}$ & $\begin{array}{l}\text { - Os plantōes de atendimento } \\
\text { passam a funcionar apenas } \\
\text { durante a a remana; } \\
\text { - Diminui a quantidade de médicos } \\
\text { disponíveis, assim como apenas } \\
\text { uma psicóloga e uma psiquiatra } \\
\text { passam a atuar no local. }\end{array}$ & $\begin{array}{l}\text { Os plantões encerram } \\
\text { funcionamento, Samarco S. A. } \\
\text { dispõe de atendimento médico } \\
\text { préviamenteragendados; } \\
\text { Os animais e as pessoas } \\
\text { apresentam problemas de } \\
\text { saúde, devido à ingestão de } \\
\text { água contaminada. }\end{array}$ \\
\hline Segurança & $\begin{array}{l}\text { - Samarco conclui as obras de } \\
\text { emergências; } \\
\text { - Implanta programas de } \\
\text { transparências para com os } \\
\text { cidadãos; } \\
\text { - Construção do dique S4 é eficaz; } \\
\text { - Garante total controle contra } \\
\text { eventos } \\
\text { rompimento da da Barragem de } \\
\text { Fundão. }\end{array}$ & 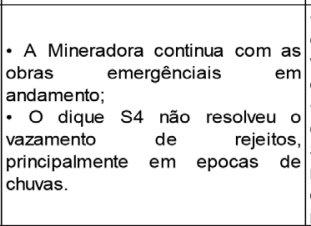 & $\begin{array}{l}\text { - Grande volume de chuvas faz } \\
\text { com que aconteça um grande } \\
\text { vazamento, causando nova onda } \\
\text { de lama; } \\
\text { - A Mineradora é inadimplente } \\
\text { com as obras e a barragem de } \\
\text { Santarem apresenta novas } \\
\text { rachaduras com vazamentos, } \\
\text { ocasionando risco de } \\
\text { rompimento. }\end{array}$ \\
\hline
\end{tabular}

Fonte: A autora (2016). 


\section{5a Etapa - Testes de consistências e ajustes, se necessários}

Nessa etapa, são elaborados testes que verificam a validação dos cenários, e, caso necessários, são feitos pelo analista ajustes mais adequados. Nesse caso, não se faz necessário ajustes aos cenários.

\section{6ㅁ Etapa-Opções estratégicas e monitoramento}

Cenário A: É importante o total envolvimento, por parte da empresa e do governo, junto às universidades, para que as condicionantes alcancem sucesso completo. Nesse cenário, o dique S4 é eficaz e proporciona maior segurança e estabilidade à comunidade.

Cenário B: Deve haver um monitoramento em relação às barragens, bem como maior fiscalização governamental para evitar sobrecarga de rejeitos, proporcionar o bom funcionamento dos equipamentos e garantir, através da transparência, segurança à população, que, muito provávelmente, não está tranquila diante das outras barragens, que também apresentam rachaduras. Visto que o dique S4 não é totalmente eficaz nesse cenário, a Samarco S. A. deve possuir um plano de emergência, pois sua ineficiência pode ocasionar eventos semelhantes aos de 2015, e, principalmente, deixar as pessoas informadas sobre os possíveis riscos.

Cenário C: Com hipótese de haver uma crise no mercado de minério, é importante criar um fundo de investimento destinado totalmente às vitimas e à recuperação dos danos causados, para tanto, é preciso, por parte da população e da Mineradora Samarco S. A., pressionar o governo para que o desastre não caia em "esquecimento" e os repasses continuem ocorrendo. O monitoramento da água deve ser contínuo, assim como o atendimento médico às vitimas, pois o ser humano é o fator mais importante aqui. As obras solicitadas pelo IBAMA devem ocorrer imediatamente, pois outro rompimento causaria ainda mais destruição, além de piorar a situação em que já se encontra, assim como a ineficiência do dique S4, que não impede vazamentos, menos ainda uma nova onda de lama. Mas, caso isso ocorra, é importante que a mineradora possua um plano para que os cidadãos tenham tempo para evacuar o local e para que a empresa consiga minimizar os danos.

\section{Conclusões}

Neste estudo, através dos objetivos propostos e da metodologia escoIhida, do embasamento teórico e da coleta de dados, foi possível elaborar uma proposta dos cenários prospectivos para os próximos 5 anos, a fim de evitar consequências semelhantes às do rompimento da barragem em Mariana - MG.

As causas do desastre foram evidenciadas no desenvolvimento deste artigo, e nota-se a irresponsabilidade por parte da Mineradora Samarco S. A. com a barragem e com os cidadãos locais, já que a empresa ignorou os alertas - por 
meio de laudos periciais - sobre o possível rompimento, sendo acusada de colocar uma quantidade de rejeitos superior ao que comportava, assim como pelo mau funcionamento de equipamentos para monitoramento de barragens. Isso demonstra que o evento poderia ter sido evitado, e essa afirmação torna-se legítima a partir do pronunciamento feito pela Comissão Extraordinária de Barragens (2015-2016), segundo a qual o desastre só aconteceu pela falta de gestão eficiente e responsável da barragem de Fundão.

Sobre a recuperação dos danos ocasionados, na segunda etapa da elaboração de cenários, na análise retrospectiva, observa-se um mapeamento das consequências ocasionadas pelo rompimento da barragem. A maioria dos prejuízos econômicos tendem a ser recuperados a longo prazo, já os danos ambientais são incertos, o mesmo acontecendo com todos os planos, prazos e a sua recuperação. No entanto, as perdas humanas são irreparáveis, e não se pode afirmar que os danos psicológicos sofridos pelas vítimas, mesmo sendo tratados, serão superados.

Por outro lado, a mineradora tem realizado ações que visam minimizar esses prejuízos, dando suporte e atendimento às pessoas atingidas, trabalhando em cima da segurança e da recuperação do meio ambiente. A fim de garantir a segurança dos locais em que se encontra este tipo de atividade, a mineração, é interessante que os órgãos públicos efetuem uma fiscalização rigorosa em outras mineradoras, pois não se sabe até que ponto elas, também, apresentam um comportamento semelhante ao da Samarco S. A.

Espera-se que as pessoas atingidas pelo desastre consigam se recuperar, que a Samarco S. A. trabalhe com transparência e tenha total segurança no controle da situação, para que os cidadãos não vivam com medo e assustados. Assim, fica-se, com este estudo, na expectativa de que o futuro reserve o melhor cenário possível para as consequências deixadas pelo desastre.

Sugere-se, para estudos futuros, o monitoramento dos planos implantados pela Samarco S. A. e seu desenvolvimento, bem como um estudo mais aprofundado sobre as causas e os prejuízos, com novos dados, os quais serão levantados nos próximos laudos. Conclui-se que o estudo foi de fundamental importância para a autora, em função do conhecimento adquirido através do embasamento teórico sobre cenários prospectivos, bem como do estudo aprofundado sobre o rompimento da barragem, sendo esse um dos principais interesses do desenvolvimento do presente artigo.

\section{Referências}

AGÊNCIA MINAS. Avaliação dos efeitos e desdobramentos do rompimento da Barragem de Fundão em Mariana - MG. Belo Horizonte: Relatório, 2016. Disponível em: <http://www.agenciaminas.mg.gov.br/ckeditor_assets/ attachments/770/relatorio_final_ft_03_02_2016_15h5min.pd $\bar{f}>$. Acesso em: 7 abr. 2016.

BETHLEM, Agrícola. Estratégia Empresarial: Conceitos, processo e administração estratégica. 5. ed. São Paulo: Atlas, 2004. 
BUARQUE, Sérgio C. Metodologia e Técnicas de Construção de Cenários Globais e Regionais. Brasília: Texto para discussão no 939, 2003. Disponível em: <http://repositorio.ipea.gov.br/bitstream/11058/2865/1/TD_939.pdf>. Acesso em: 15 mar. 2016.

COMISSÃO EXTRAORDINÁRIA DE BARRAGENS. Relatório final. Belo Horizonte: 2015-2016. Disponível em: <http://www.rogeriocorreia.com.br/wp-content/ uploads/2016/07/relatorio_final_da_comissao_de_barragens.pdf>. Acesso em: 19 set. 2016.

GODET, Michel. Manual de prospectiva estratégica: da antecipação a acção. Lisboa: Publicações Dom Quixote, 1993.

IBAMA. Ibama aplica sétima multa à Mineradora Samarco e nega adiamento de prazo para retirada de rejeitos. 2016. Disponível em: <http://www.ibama.gov. $\mathrm{br} /$ publicadas/ibama-aplica-multa-de-r-1-milhao-a-mineradora-samarco-e-negaadiamento-de-prazo-para-retirada-de-rejeitos>. Acesso em: 1 out. 2016.

HEIJDEN. Kees Van Der. Planejamento de Cenários: a arte da conversação estratégica. Porto Alegre: Bookman, 2004.

MARCIAL, Elaine Coutinho; GRUMBACH, Raul José dos Santos. Cenários Prospectivos: como construir um futuro melhor. 5. ed. Rio de Janeiro: FGV, 2008.

MILANEZ, Bruno et al. Antes fosse mais leve a carga: avaliação dos impactos econômicos, políticos e sociais do desastre da Samarco/Vale/BHO em Mariana (MG). Mimeo: 2015. Disponível em: <http://www.ufjf.br/poemas/files/2014/07/ PoEMAS-2015-Antes-fosse-mais-leve-a-carga-vers\%C3\%A3o-final.pdf>. Acesso em: 20 mar. 2016.

O TEMPO. Veja as imagens de satélite do 'antes' e 'depois' de Bento Rodrigues. 2015. Disponível em: <http://www.otempo.com.br/hotsites/ mar-de-lama/veja-as-imagens-de-sat\%C3\%A9lite-do-antes-e-depois-de-bentorodrigues-1.1163164>. Acesso em: 3 abr. 2016.

MINISTÉRIO PÚBLICO FEDERAL. MPF denuncia 26 por tragédia em Mariana (MG). 2016. Disponível em: <http://www.mpf.mp.br/es/sala-de-imprensa/ noticias-es/mpf-denuncia-26-por-tragedia-em-mariana-mg>. Acesso em: 24 out. 2016.

ONUBR. Desastre de Marina (MG): medidas do governo, Vale e BHP Billiton foram claramente insuficientes. 2015. Disponível em: <https://nacoesunidas. org/desastre-de-mariana-mg-medidas-do-governo-vale-e-bhp-billiton-foramclaramente-insuficientes/>. Acesso em: 3 abr. 2016.

REVISTA GALILEU. Lei de Murphy - quando tudo dá errado. Edição 1048. 2003. Disponível em: <http://www.exatas.net/lei_murphy.pdf>. Acesso em: 22 mar. 2016.

SAMARCO. Dossiê: Balanço das ações. 2016. Disponível em: <http://www. samarco.com/wp-content/uploads/2015/12/Dossie_reduzido_19_05.pdf>. Acesso em: 4 jun. 2016.

SCHWARTZ, Peter. A Arte da Visão a Longo Prazo: Planejando o futuro em um mundo de incertezas. 2. ed. São Paulo: Best Seller, 2003. 
SOUZA, Ivan Domicio da Silva; TAKAHASHI, Vania Passarini. A visão do Futuro por meio de Cenários Prospectivos: Uma ferramenta para antecipação da Inovação Disruptiva. São Paulo: Future Studies Reseach Journal, 2012. Disponível em: <http://www.spell.org.br/documentos/ver/9222/a-visao-de-futuro-por-meiode-cenarios-prospect--->. Acesso em: 14 mar. 2016.

TARAPANOFF, Kira (Org.). Inteligência organizacional e competitiva. Brasília: UNB, 2001.

TRIBUNAL DE JUSTIÇA DE MINAS GERAIS. Justiça suspende licenças ambientais do Complexo Germano da Samarco. 2016. Disponível em: <http://www.tjmg. jus.br/portal/imprensa/noticias/justica-suspende-licencas-ambientais-docomplexo-germano-da-samarco.htm\#.V_OYqvkrLIU>. Acesso em: 20 set. 2016. 